\title{
ESTUDO DA UTILIZAÇÃO DAS FERRAMENTAS DA QUALIDADE PARA ANÁLISE DE CAUSA RAIZ DA BAIXA PERFORMANCE DE ATENDIMENTO EM UMA EMPRESA DE TELECOMUNICAÇÕES
}

\author{
STUDY OF THE USE OF QUALITY TOOLS TO ANALYZE THE ROOT CAUSE OF LOW SERVICE \\ PERFORMANCE IN A TELECOMMUNICATION COMPANY
}

\author{
Catala Racile Ruela Silva ${ }^{1^{*}}$ \& Wilson Rodrigues de Souza Junior ${ }^{2}$ \\ ${ }^{1 * 2}$ Centro Universitário Salesiano - Unisales \\ ${ }^{1 *}$ catalaruela@gmail.com ${ }^{2}$ wjunior@ $@$ salesiano.br
}

\section{ARTIGO INFO.}

\section{Recebido em: 20.12.2021}

Aprovado em: 21.02.2022

Disponibilizado em: 08.03.2022

Palavras-chave:

Análise e solução de problemas; Qualidade;

Ferramentas da qualidade.

KEYWORDS:

Analysis and problem solving; Quality; Quality tools.

*Autor Correspondente: Silva, C. R. R.

\section{RESUMO}

A abordagem sistematizada de problemas é um dos aspectos mais importantes de um programa da qualidade. Diversas ferramentas foram desenvolvidas para auxiliar o profissional a compreender os problemas que ocorrem em seu dia a dia, achar a causa raiz e encontrar soluções adequadas para eles. O trabalho proposto teve por objetivo aplicar ferramentas da área de gestão da qualidade, trabalhando todos os seus aspectos de resolução de problemas, para encontrar a causa raiz da avaliação ruim realizada pelo cliente acerca do atendimento, com o intuito de melhorar a nota de satisfação (avaliação realizada pelo cliente) de atendimento de uma campanha de atendimento ao cliente. Dentre as ferramentas que foram utilizadas, estão: gráfico de Pareto, diagrama de causa e efeito, Matriz GUT e $5 \mathrm{~W} 2 \mathrm{H}$. Os resultados encontrados foram ações de melhorias contínuas que contribuirão para melhora do indicador da operação, confirmando o objetivo da gestão da qualidade, a satisfação total dos clientes.

\begin{abstract}
The systematic approach to problems is one of the most important aspects of a quality program. Several tools were developed to help professionals understand the problems that occur in their daily lives, find the root cause and find adequate solutions for them. The proposed work aimed to apply tools from the quality management area, working on all aspects of problem solving, to find the root cause of the poor customer service evaluation, in order to improve the satisfaction score (customer service assessment) of a customer service campaign. Among the tools that were used are: Pareto chart, cause and effect diagram, GUT matrix and $5 \mathrm{~W} 2 \mathrm{H}$. The result found was continuous improvement actions that will contribute to improving the operation indicator, confirming the objective of quality management, total customer satisfaction.
\end{abstract}




\section{INTRODUÇÃO}

A gestão de qualidade é um assunto frequente nas empresas, pois os clientes estão cada vez mais exigentes e seletivos. Isso significa que, sem um padrão adequado, nenhuma empresa consegue se manter no mercado, vender e competir com as outras. Segundo Neto e Chiquetano (2020), todas as organizações de manufatura ou de serviços, procuram alcançar o sucesso em seu empreendimento, mas esse propósito traz na bagagem a responsabilidade da entrega correta de um produto ou serviço. E, caso isso não ocorra, haverá a inevitável perda de dinheiro e tempo, abalando diretamente a subsistência da organização.

Ainda segundo Neto e Chiquetano (2020), as ferramentas da qualidade, quando aplicadas corretamente dentro de uma organização, em suma possuem: processos desenhados, passo a passo, controle do que foi feito e desfeito, medidor de atividades realizadas etc., a fim de que todos os processos possam funcionar da melhor forma possível. E toda e qualquer atividade realizada precisa de melhorias, para que a empresa se mantenha nas disputas de mercado e não se tornem obsoletas.

Conforme citado por Neto e Chiquetano (2020), "melhorar processos é uma ação básica para as organizações responderem às mudanças que ocorrem constantemente em seu ambiente de atuação e para manter o sistema produtivo competitivo" e, "compreender e melhorar a qualidade são fatores-chave que conduzem ao sucesso, ao crescimento e a uma melhor posição de competitividade de uma empresa". Com isso, o problema deste trabalho é: Quando há nota de satisfação ruim na avaliação do cliente em relação ao atendimento prestado, é necessário descobrir por que o atendimento não foi satisfatório, identificar a causa raiz deste mal atendimento e propor soluções de melhoria. Como as ferramentas da qualidade podem propor soluções?

Tem-se como hipótese que a partir da utilização das ferramentas da qualidade, será possível encontrar a causa raiz da avaliação ruim realizada por parte do cliente referente ao atendimento prestado e estabelecer o plano de ação necessário para mitigar o problema e obter melhoria contínua nos processos de atendimento.

Deste modo, com este questionamento, a partir de resultados de uma empresa de telecomunicações (chamada de Empresa A para confidencialidade dos dados), o objetivo geral deste trabalho é analisar como as ferramentas da qualidade, se aplicadas corretamente, auxiliam de forma positiva a encontrar soluções de melhoria de performance para com o atendimento ao cliente em uma empresa de telecomunicações.

A proposta deste trabalho é analisar e solidificar a pesquisa realizada acerca das ferramentas da qualidade e suas funcionalidades, para a composição da fundamentação teórica sobre o tema apresentado.

Conforme afirma Mello et al. (2017), em manufaturas ou empresas de prestação de serviço, a procura do verdadeiro propósito, que é o satisfatório atendimento ao cliente, deve estar elencada no empenho para conseguir o menor custo com a melhor qualidade. A busca da melhoria contínua cria uma cultura interna de colaboração, de consciência e, principalmente, da organização com inteligência e segurança no caminho do progresso e expansão empresarial. 
Citação (APA): Silva, C. R. R. \& Souza, W. R. de S., Jr. (2022). Estudo da utilização das ferramentas da qualidade para análise de causa raiz da baixa performance de atendimento em uma empresa de telecomunicações. Brazilian Journal of Production Engineering, 8(2), Edição Especial "Ciência na Prática", 145-162.

Fundamentado no objetivo de compreender os processos para melhoria contínua, foi realizada uma pesquisa de campo na empresa A, com o intuito de identificar as avaliações dos clientes que possuem plano de celular para e entraram em contato com o serviço de atendimento ao cliente. Após aprovação para a pesquisa, foi possível analisar em uma base de dados, informações de avaliações prestadas por clientes, onde foi encontrado o insumo para a realização das ações práticas com a utilização das ferramentas da qualidade, suas funcionalidades e conclusões. No texto será apresentado o estudo do caso acerca do tema, com o passo a passo de análise de causa raiz, formas de análises baseadas nas ferramentas da qualidade e possível criação de plano de ação para solucionar a oportunidade encontrada.

\section{REFERENCIAL TEÓRICO}

\subsection{Gestão Da Qualidade}

A definição de qualidade pode ser alusiva, afinal de contas um produto pode ter qualidade para uma pessoa, enquanto para a outra não, contudo o conceito evoluiu ao longo dos anos. Em 1950, qualidade era a plenitude técnica, porém por causa da troca do perfil vendedor para comprador, a ideia tornou-se mais associada às exigências do cliente (Neto e Chiquetano, 2020). Porém, representando a inclinação futura, a Qualidade seria a total satisfação do cliente. Tendo como apoio as experiências do cliente, seu entendimento e sua cronologia, tudo isso passa a ser considerável na construção do anseio do cliente, alterando a definição de qualidade para cada indivíduo. Slack nos dá um exemplo da seguinte forma, "uma pessoa pode perceber um voo de longo trajeto como parte interessante de um feriado; a pessoa do assento ao lado pode vê-lo como uma tarefa necessária para chegar a uma reunião de negócio" (Neto e Chiquetano, 2020). Dessa forma a concepção de qualidade mudou ao longo das décadas e tem se tornado mais favorável ao cliente do que às organizações.

Nestas circunstâncias, a gestão da qualidade se tornou uma estratégia que ajuda o gestor a compreender os anseios dos clientes. Ela é vista como uma ação de melhoria dentro da organização, junto com o acompanhamento dos processos pertinentes à qualidade, diminuindo a inconstância dos processos, produtos e serviços, é a "totalidade das funções envolvidas na determinação e obtenção da qualidade” (Neto e Chiquetano, 2020).

Segundo a Norma Brasileira ISO 9001 (2015), a gestão da qualidade apresenta sete princípios, apresentados na figura 1, que podem ser usados pelos gestores para conduzir a organização na melhoria do seu desempenho. 
Citação (APA): Silva, C. R. R. \& Souza, W. R. de S., Jr. (2022). Estudo da utilização das ferramentas da qualidade para análise de causa raiz da baixa performance de atendimento em uma empresa de telecomunicações. Brazilian Journal of Production Engineering, 8(2), Edição Especial "Ciência na Prática", 145-162.

Figura 1. 7 princípios da gestão da qualidade

\begin{abstract}
1. Foco no cliente
O cliente precisa se sentir satisfeito no final do processo. Ao receber o seu produto ou serviço, ele deve sentir que, minimamente, as suas expectativas são atendidas. $Q$ ideal é exceder os anseios do cliente, indo além da resolução do problema que ele espera.
\end{abstract}

\title{
2. Liderança
}

A liderança é ponto-chave para cumprir as exigências e expectativas do cliente. Ela conduzirá a sua equipe a processos mais eficientes, bem como transmitirá os pilares da qualidade para os funcionários.

3. Engajamento das pessoas

Todos aqueles que estão envolvidos na cadeia produtiva precisam ser aptos a exercer as suas funções de modo eficiente, bem como também vestir a camisa. Equipes não comprometidas podem prejudicar a qualidade da produção.

\section{Abordagem de processo}

É preciso compreender como deve ser o processo como um todo, a fim de manter a qualidade impecável em todas as partes da produção e execução, bem como ter um padrão único para todos os produtos e/ou serviços elaborados.

\section{Melhoria}

Quando um erro é encontrado, é importante buscar a melhoria para parar de prejudicar o processo.

Para isso é importante estar atento sempre, mensurando e monitorando o que está sendo realizado.

\section{Tomada de decisão baseada em evidência}

É importante que todas as decisões tomadas sejam baseadas em informações reais, conduzindo a atitudes mais inteligentes.

\section{Gestão do relacionamento}

Nã̃ se encerra a sua relação com o cliente quando o produto ou o serviço é entregue. É necessário estabelecer uma boa relação com ele no pós-venda, assim também é necessário um bom relacionamento entre os setores da empresa, entre líderes e colaboradores, e entre empresa e fornecedores.

Fonte: ISO 9001 (2015)

Dentre as ferramentas da qualidade que é possível utilizar, segue abaixo o que será incluído neste estudo de caso:

\subsection{Ferramentas da Qualidade}

Segundo De Souza Coelho et al. (2016), declarando que a qualidade abrange a conformidade entre o planejado e o realizado, as empresas precisam estabelecer padrões e indicadores mensuráveis para que seja possível realizar uma análise. Conforme citado por mesmo autor, as sete ferramentas da qualidade são um conjunto de instrumentos estatísticos de uso consagrado para melhoria da qualidade de produtos, serviços e processos. As sete ferramentas da qualidade são:

a) Fluxograma ou diagrama de processo;

b) Diagrama de causa e efeito;

c) Diagrama de Pareto;

d) Histograma;

e) Gráfico de controle;

f) Folha de verificação; e,

g) Diagrama de dispersão. 
O estabelecimento das ferramentas da qualidade pode sofrer modificações, dependendo do contexto da aplicação. Essas alterações podem ocorrer na sequência de utilização dos métodos ou na quantidade de métodos utilizados. A próxima seção inicia a apresentação das sete ferramentas básicas de qualidade.

\subsubsection{Gráfico de Pareto}

Foi concebido pelo engenheiro e economista italiano Vilfredo Pareto, que analisou a distribuição de riqueza em seu país e buscou descrevê-la estatisticamente. Ao fazer isso, descobriu que apenas $20 \%$ da população possuía a maior parte da riqueza. Fez a demonstração dessa distribuição graficamente, em uma curva cumulativa que ficou conhecida como a curva de Pareto (De Souza Coelho et al., 2016). Posteriormente a mesma ideia foi levada pelos estatísticos ao contexto produtivo e dos serviços, mostrando-se aplicável também nesses ambientes. O Diagrama de Pareto é um gráfico de barras que ordena as frequências das ocorrências, da maior para a menor, permitindo a priorização dos problemas. Serve para analisar e identificar as causas ou problemas mais importantes.

Sua composição acontece a partir dos seguintes passos:

a) Selecionar os problemas a serem comparados e estabelecer uma ordem de prioridades para sua análise;

b) Selecionar um padrão de comparação;

c) Selecionar um período de tempo para ser analisado;

d) Reunir os dados necessários dentro de cada categoria;

e) Comparar a frequência ou custo de cada categoria com relação a todas as outras;

f) Listar as categorias da esquerda para a direita no eixo horizontal, em ordem decrescente;

g) Acima de cada classificação ou categoria deve-se desenhar um retângulo ou barra cuja altura corresponda ao valor dessa variável na classificação escolhida.

O resultado é uma ilustração simples e que facilita a aplicação de esforços para a análise de problemas (De Souza Coelho et al., 2016).

Figura 2. Exemplo de Gráfico de Pareto

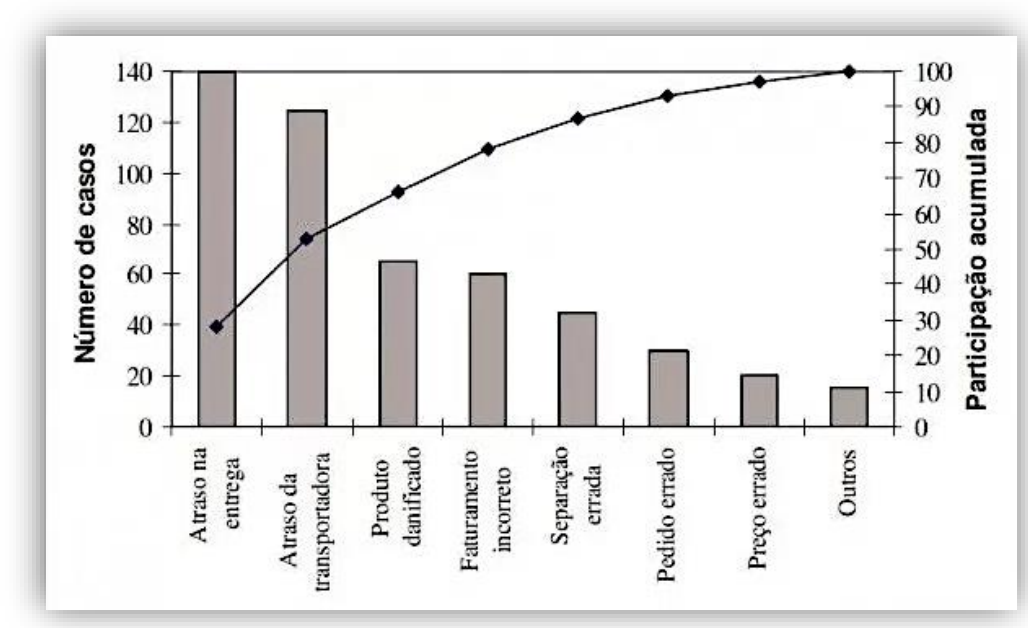

Fonte: Blog da Qualidade, Gráfico de Pareto

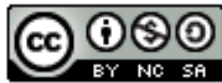




\subsubsection{Diagrama de Ishikawa}

Também conhecido como "Diagrama de Causa e Efeito", "Diagrama Espinha-de-peixe" ou "Diagrama 6M", é uma ferramenta gráfica utilizada pela administração para o gerenciamento e o controle da qualidade em processos diversos. Foi originalmente proposto pelo engenheiro químico Kaoru Ishikawa em 1943, visando identificar, explorar e ressaltar todas as causas possíveis de um problema ou questão específica (De Souza Coelho et al., 2016). Esta ferramenta pode ser utilizada para organizar as ideias obtidas no brainstorming, contribuindo para a análise e identificação das possíveis causas de um problema e, também, identificação de suas soluções. O diagrama de Ishikawa é também conhecido como $6 \mathrm{M}$, pois ele é dividido em seis causas possíveis: máquina, mão de obra, material, método, meio ambiente e medida. Para organizar este diagrama primeiro, é identificado o efeito do problema a ser estudado, que é registrado no desenho que representa a cabeça do peixe e, em seguida, são registradas, nas espinhas, as causas que podem provocar o problema (Corrêa e Oliveira, 2017).

Figura 3. Exemplo de Diagrama de Ishikawa

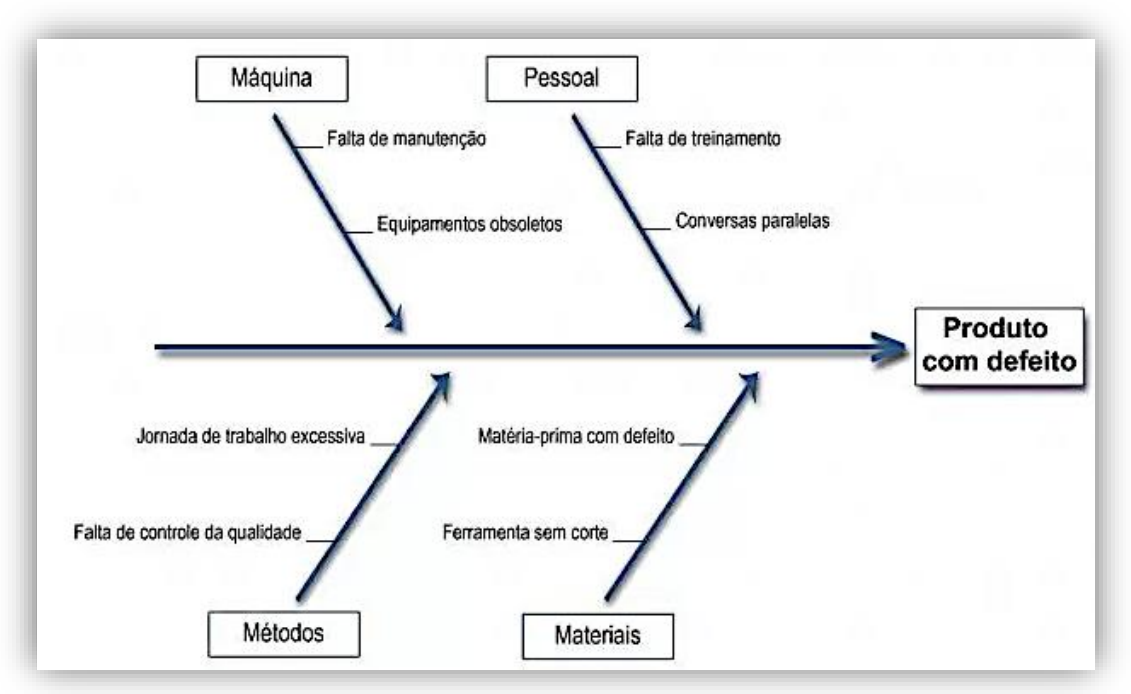

Fonte: Blog da Qualidade, Diagrama de Causa e Efeito

\subsubsection{Brainstorming}

Conforme citado por Muniz et al. (2016), o Brainstorming é uma forma de trabalho em equipe que tem por objetivo levantar as principais ideias a respeito de um determinado tema em um tempo curto, ou seja, o principal objetivo é buscar um número considerável de ideias/causas da oportunidade identificada sem o receio de críticas. É possível obter mais de 100 ideias em uma reunião de uma a duas horas. Os pensamentos iniciais são geralmente os mais perceptíveis e as ideias mais inovadoras, com melhor consistência aparece no final da reunião. Segundo Muniz et al., uma indicação da solução do problema é determinada quando o grupo como um todo identifica que aquela ideia resolverá o problema, mostrando assim o que se espera de uma ferramenta da qualidade. 


\subsubsection{Matriz Gut (Gravidade, Urgência, Tendência)}

Consiste em uma ferramenta para priorização de processos para resolução de problemas e seu grau de importância (Muniz et al., 2016). Neste trecho, o cenário que o autor coloca em pauta é equiparar em tabelas de prioridades as causas raízes e a partir deste ponto, ter uma lista de resolução baseada no nível de risco e urgência. Esta ferramenta atualmente é quase obrigatória para resoluções de cenários problemáticos encontrados nas organizações, pois prioriza os cenários a serem tratados com mais urgência e que possam ter maior tendência ao erro contínuo e alta proporção à gravidade, causando, por exemplo, uma parada de produção.

\subsubsection{W2H}

A ferramenta $5 \mathrm{~W} 2 \mathrm{H}$ tem sua origem na indústria automobilística, especificamente no Japão, onde foi criada. Posteriormente foi estendido para outras áreas, sempre com o objetivo de ajudar a supervisionar o passo a passo da concepção de um projeto ou plano de ação. (Freitas et. al., 2020). A utilização dessa ferramenta permite que um processo de execução seja dividido em etapas estruturadas a partir de perguntas com o objetivo de descobrir falhas que impedem o término adequado do processo. As questões têm como objetivo gerar respostas que esclareçam o que precisa ser resolvido ou que estruture as ideias para solução dos problemas.

A metodologia 5W2H (What, Why, Who, Where, When, How and How Much), é composta por perguntas em inglês que, traduzidas para português ficam: “O que?", "Por que?", "Quem?”, “Onde?”, “Quando?”, “Como?” e "Quanto?”, e submetidas a outras ferramentas da qualidade, apresentam o entendimento necessário para identificação de problema e apontamento do alvo com problemas principal, para solução, sendo também utilizada como plano de ação (Freitas et. al., 2020).

\subsubsection{Porques}

A análise dos 5 Porques é um método simples e eficaz que contribui para a identificação de causas de problemas, análise de causa raiz, principalmente utilizada na área da qualidade, mas pode ser aplicada em qualquer área. Os 5 porquês é uma ferramenta criada por Taiichi Ono, considerado o pai do Sistema Toyota de produção, que consiste em realizar a pergunta "Por quê" cinco vezes para identificação e compreensão da causa do problema. Não necessariamente é preciso realizar as cinco perguntas, desde que a causa raiz do problema seja encontrado.

\section{METODOLOGIA}

O método científico é entendido como um "[...] conjunto de procedimentos intelectuais e técnicos adotados para se atingir o conhecimento desejado [...]”' (Da Silva Melo et al., 2016). Assim, neste estudo, será utilizada a coleta de informações de maneira que o resultado da aplicação do método demonstrasse o mais próximo da realidade dos fatos.

O trabalho será desenvolvido com base em uma pesquisa com abordagem quali-quantitativa. Através da solicitação de pesquisa junto ao RH e Setor Jurídico, confirmando a confidencialidade dos dados de clientes, foi possível a coleta de dados primários, que se deu através de acesso ao banco de dados com informações dos atendimentos prestados e entrevistas junto a 18 colaboradores do setor de qualidade da empresa pesquisada, sobre as oportunidades encontradas em uma campanha de atendimento celular e sua performance de resolução de 
problemas do cliente, identificando o indicador "Avaliação de Satisfação" - notas 1 a 5 realizado pelo cliente (1 - Muito Insatisfeito, 2 - Insatisfeito, 3 - Neutro, 4 - Satisfeito e 5 Muito Satisfeito) como indicador para nota de atendimento.

a. No primeiro momento foram levantados todos os dados que diz respeito a como o atendimento é realizado, procedimentos, prazos, processos de atendimento e fluxos de resposta com o cliente. Se necessário, as ferramentas da qualidade (fluxograma) já serão utilizadas para melhor entendimento do passo a passo (pesquisa feita junto aos colaboradores da área de qualidade);

b. Na fase 2 foram coletados os dados de resultados de atendimento que estão em depreciação (fora da meta) para dar início às análises. Não houve metodologia estruturada;

c. Na fase 3 foram utilizadas as demais ferramentas da qualidade (Diagrama de Pareto, Diagrama de Ishikawa, etc.) para identificação da causa raiz;

d. Na fase 4 os resultados foram apresentados acerca da pesquisa efetuada e das análises realizadas, sendo positivos ou negativos.

\section{RESULTADOS E DISCUSSÃO}

Em relação a empresa objeto de estudo deste artigo, trata-se de uma companhia de telecomunicações que presta serviço de Contact Center e Vendas, realizando atendimento estratégico com células de Ouvidoria, Anatel, Atendimento técnico e BackOffice.

As operadoras de telefonia, TV por assinatura, Banda Larga, Telefonia Fixa, são avaliadas pelos clientes após a conclusão da solicitação, que fica disponível publicamente no Site da Anatel: https://apps.anatel.gov.br/anatelconsumidor/. Desta forma, é possível acompanhar os resultados e comparar os melhores atendimentos/produtos. Segue abaixo um gráfico com a nota de satisfação do cliente, mostrando o desempenho das operadoras.

Figura 4. Nota de Satisfação de Atendimento das principais operadoras do Brasil

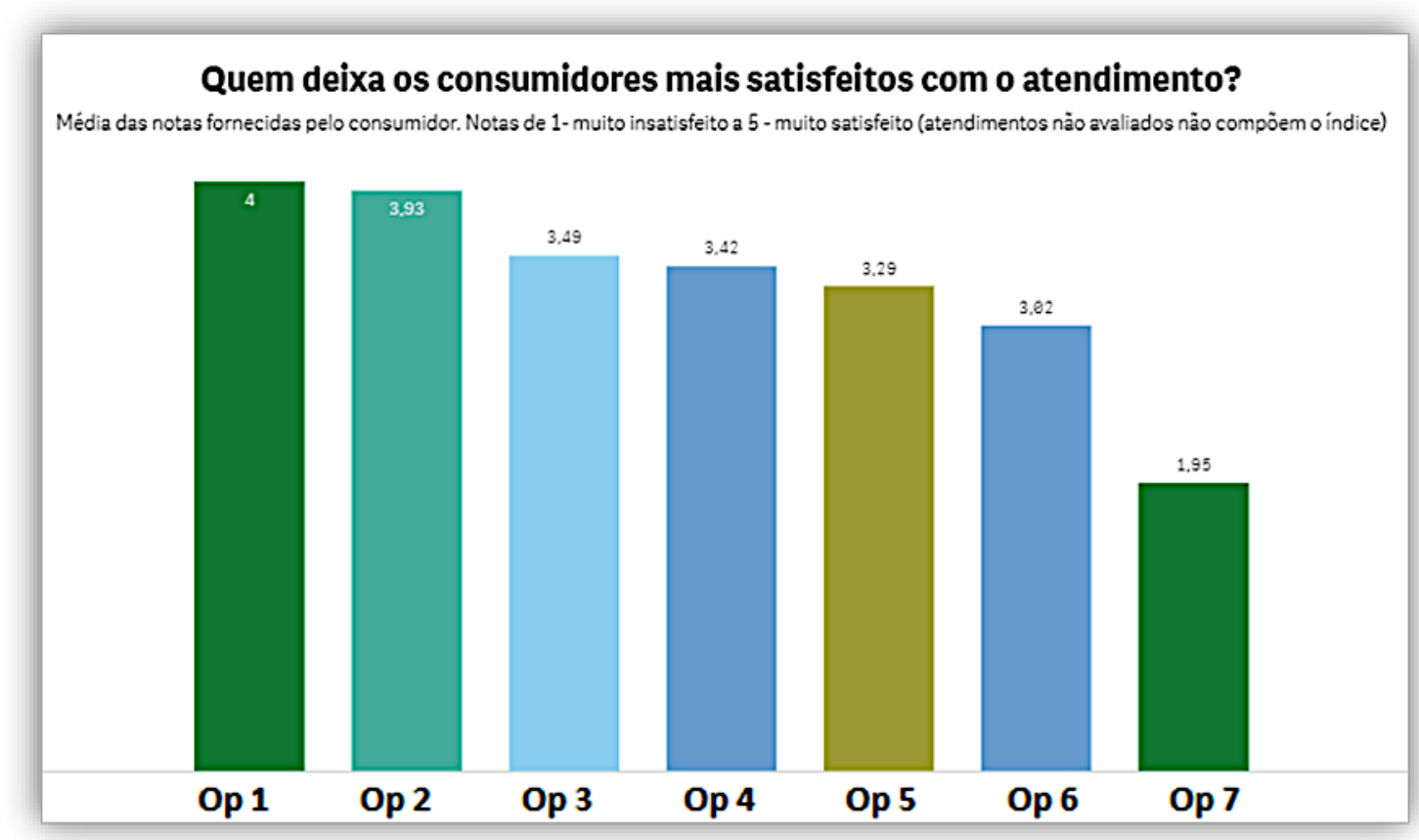

Fonte: https://apps.anatel.gov.br/anatelconsumidor/DesempenhoPrestadorasHome.aspx

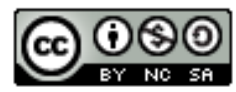


Inicialmente, foi realizado uma visita à Empresa A, para conhecer os fluxos e o que será estudado. Após a disponibilização da base de dados em que estão as avaliações dos clientes, foram feitas as análises: Foi pesquisado a forma de como o atendimento às reclamações do cliente, funciona na empresa, para melhor entendimento da base de casos; Foi disponibilizada a base de avaliações realizadas por clientes em Setembro/2021; Ao todo, foram encontrados 7.426 registros de atendimentos com avaliações realizadas pelo cliente após a prestação do atendimento pela operadora; Com os registros disponibilizados, foram filtradas as avaliações com notas de 1 a 3 para analisar o motivo do cliente avaliar mal o atendimento prestado e realizada a junção dos motivos e sub-motivos e a quantidade por tipo de reclamação.

Determinou o fluxograma de atendimento às reclamações, conforme a Figura 5.

Figura 5. Fluxograma de Atendimento ao Cliente - reclamações

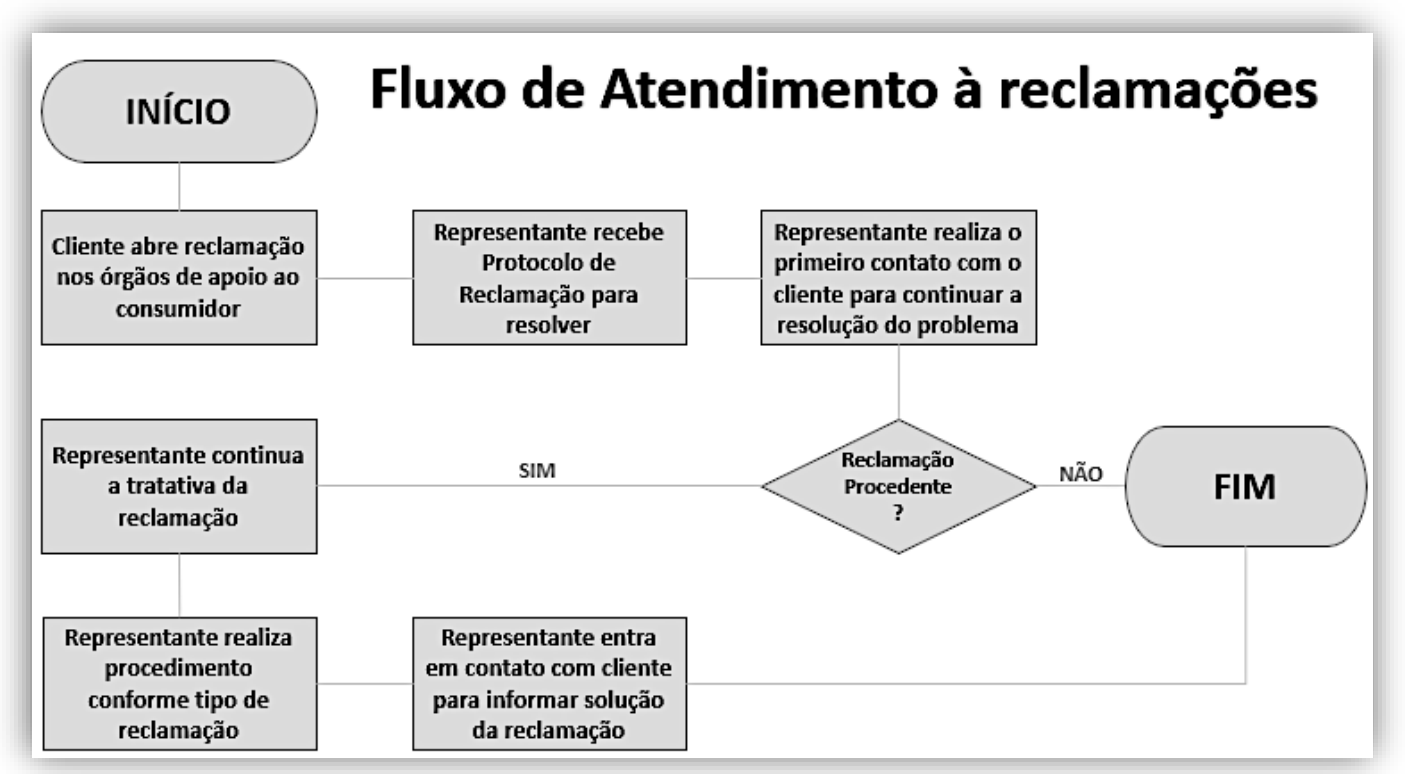

Fonte: Base de Avaliações disponibilizada pela Empresa A

Foram encontradas 2.083 avaliações de 1 a 3 na base de reclamações da operadora.

Tabela 1. Notas Detratoras - avaliações ruins

\begin{tabular}{ccc} 
NOTA DE AVALIAÇÃO & QUANTIDADE & $\%$ PART \\
1 & 1.506 & $72,30 \%$ \\
2 & 205 & $9,84 \%$ \\
3 & 372 & $17,86 \%$ \\
\hline Total Geral & $\mathbf{2 . 0 8 3}$ & $\mathbf{1 0 0 , 0 0 \%}$
\end{tabular}

Fonte: Base de Avaliações disponibilizada pela Empresa A

Realizada a utilização do gráfico de Pareto para identificar os principais motivos de entrada que levam os clientes a entrarem em contato com o atendimento da operadora e foram encontrados 6 motivos principais que detém $80 \%$ do total de reclamações com avaliações de 1 a 3 , conforme a Figura 6.

Os itens significativos, priorizados no gráfico de Pareto, totalizam 1.664 avaliações do total da base. Deste volume, 72,9\% são de avaliações com Nota 1, 9,4\% são de Nota 2 e 17,7\% são de avaliações identificadas com Nota 3.

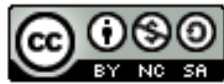


Figura 6. Diagrama de Pareto - Principais Motivos de Entrada com avaliações de 1 a 3

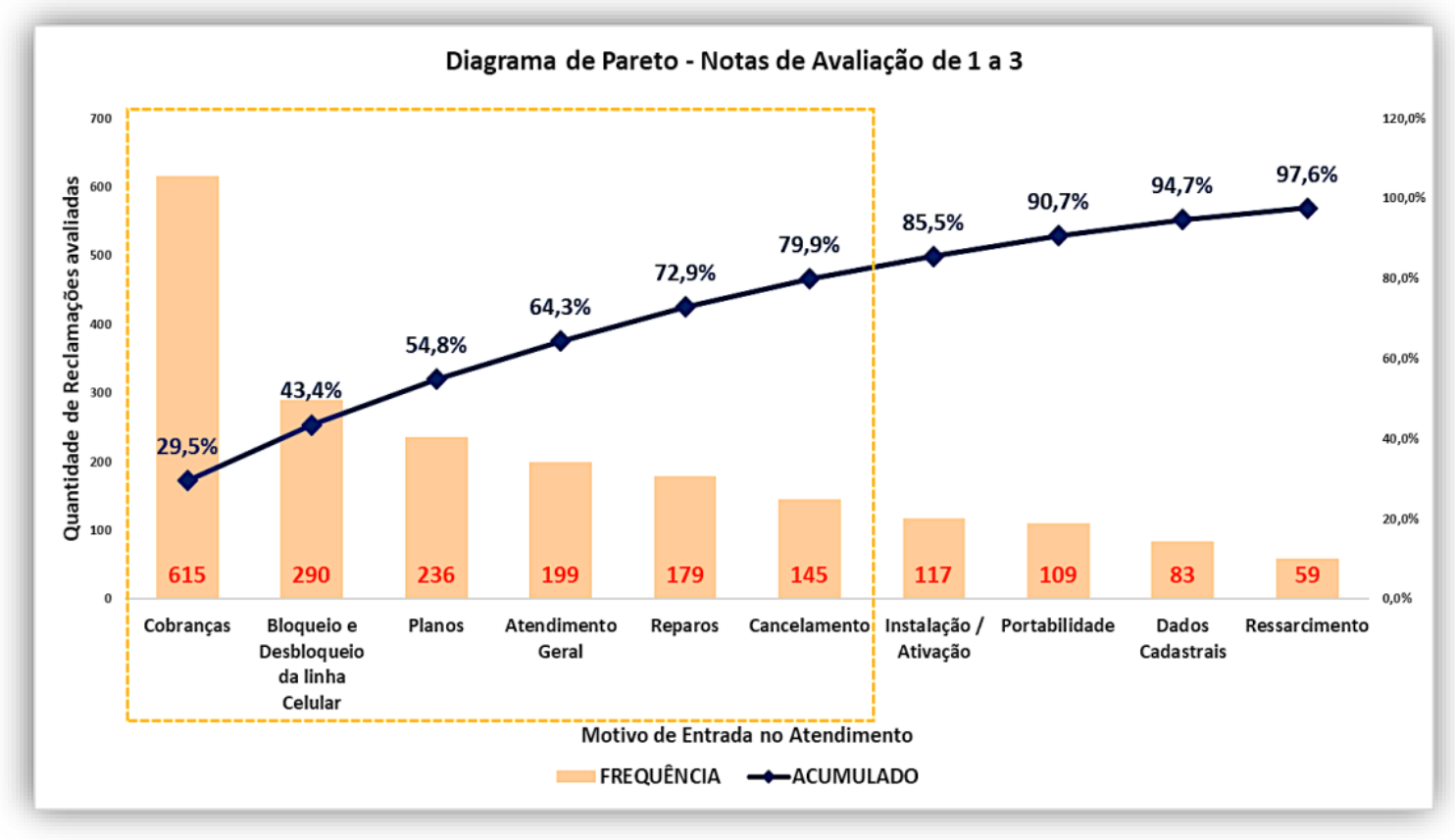

Fonte: Base de Avaliações disponibilizada pela Empresa A

Na Figura 7 é possivel identificar o percentual de participação de notas detratoras dos principais motivos de entrada. A Nota 1, representada em vermelho, indica que a maior participação das avaliações por motivo de entrada são de clientes que ficaram Muito Insatisfeitos. Logo após vem a Nota 2, representada em vermelho, que tem peso intermediário e por último, porém com peso médio, é possível ver a participação da Nota 3, em amarelo, de clientes que não estão insatisfeitos, mas que também não estão satisfeitos.

Figura 7. Participação do volume de avaliações por nota por motivo de entrada

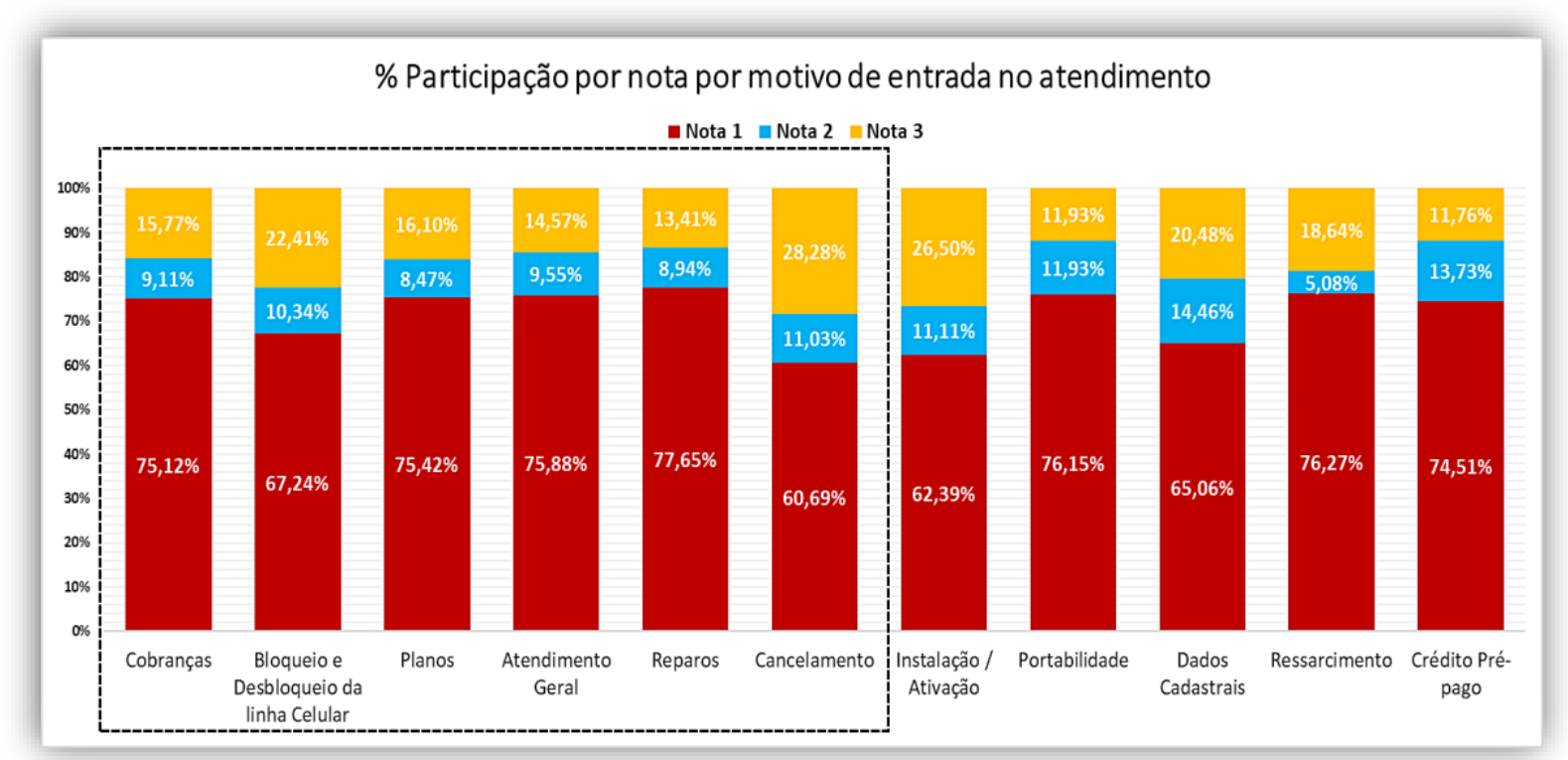

Fonte: Base de Avaliações disponibilizada pela Empresa A

\section{(9) $\odot \Theta(\odot$}


Na Figura 8 foi possível identificar os motivos de fechamento dos casos que possuem $80 \%$ de peso no Diagrama de Pareto. Foi possível identificar que quando o cenário é de processo não cumprido (primeiro lugar em nota 1) temos maior incidência de notas ruins.

Figura 8. Principais Motivos de fechamento do caso com notas de 1 a 3

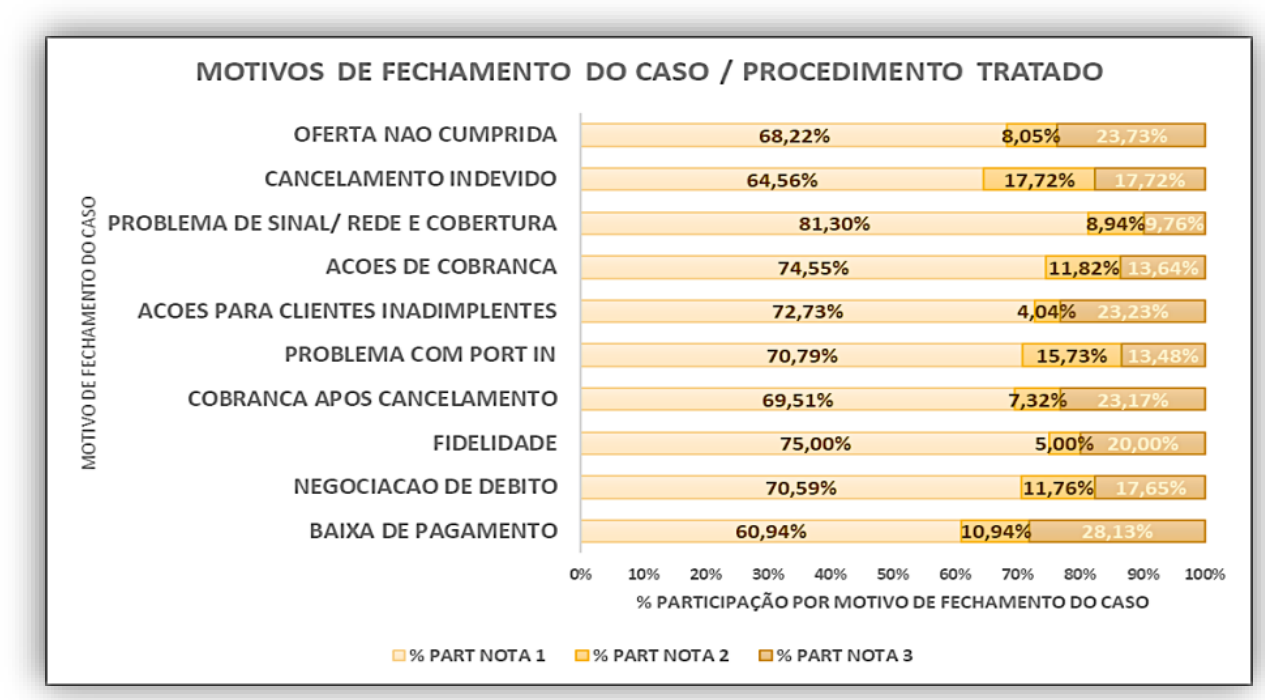

Fonte: Base de Avaliações disponibilizada pela Empresa A

Após a identificação dos motivos principais de acordo com o Diagrama de Pareto, foi possível realizar um Brainstorming junto aos analistas da qualidade. Foram feitas 3 reuniões com 18 pessoas, em que foram discutidos os principais problemas enfrentados para entregar o melhor resultado de atendimento ao cliente. A partir da ferramenta dos 5 Porques, conforme a Figura 9, foi traçado o segundo passo para descobrir a causa raiz da queda de nota de satisfação do cliente junto à operadora. Utilizada categorias para estratificar cada cenário de problemas que poderiam acarretar em um mau atendimento e, consequentemente, uma nota baixa de avaliação. Logo após foi utilizado o Diagrama de Ishikawa para identificação dos sub-itens ofensores. Foi identificado as seguintes causas para a avaliação ruim do cliente, seguindo todas as categorias: Máquina - Sistema sem as ferramentas corretas para atendimento mais ágil e correto; Mão de Obra - Falta de padronização para procedimento e Falta de resposta padrão para fechamento dos casos (caso do cliente); Material - Problema físico com o aparelho do cliente e Máquina com defeitos; Medição de Resultados - Falta de relatório específico para acompanhamento e Falta de relatório específico para identificação das causas de avaliação ruim; Meio Ambiente Falta de repasse dos novos processos aos funcionários e Falta de estrutura de repasse de informações para operação que trata as reclamações; por fim a categoria de Método - Falta de relatórios de controle qualitativo e Falta de relatórios de acompanhamento de volume entrante de reclamações. 
Citação (APA): Silva, C. R. R. \& Souza, W. R. de S., Jr. (2022). Estudo da utilização das ferramentas da qualidade para análise de causa raiz da baixa performance de atendimento em uma empresa de telecomunicações. Brazilian Journal of Production Engineering, 8(2), Edição Especial "Ciência na Prática", 145-162.

Figura 9. Análise de Causas - 5 Porquês

\begin{tabular}{|c|c|c|c|c|c|c|c|c|}
\hline EFEITO & CATEGORIA & CAUSA & POR QUE? 1 & POR QUE? 2 & POR QUE? 3 & POR QUE? 4 & PORQUE? 5 & CAUSA RAIZ \\
\hline \multirow{5}{*}{$\begin{array}{c}\text { ITEM: } \\
\text { AVALIAÇÃO DO } \\
\text { CLIENTE ENTRE } \\
\text { MUITO RUIM, } \\
\text { RUIM E REGULAR } \\
\text { (NOTAS } 1 \text { A 3) }\end{array}$} & MÁQUINA & $\begin{array}{l}\text { Máquina trava ao } \\
\text { representante tentar } \\
\text { utilizar }\end{array}$ & $\begin{array}{c}\text { Máquina antiga sem } \\
\text { atualizações }\end{array}$ & $\begin{array}{l}\text { Maquina não possui } \\
\text { manutenção coreta }\end{array}$ & $\begin{array}{l}\text { Sistema sem as } \\
\text { ferramentas } \\
\text { corretas para } \\
\text { atendimento mais } \\
\text { ágil e correto }\end{array}$ & & & $\begin{array}{c}\text { Sistema sem as } \\
\text { ferramentas corretas } \\
\text { para atendimento } \\
\text { mais ágil e correto }\end{array}$ \\
\hline & \multirow{2}{*}{$\begin{array}{l}\text { MÃO DE } \\
\text { OBRA }\end{array}$} & $\begin{array}{l}\text { Representante erra } \\
\text { procedimento }\end{array}$ & $\begin{array}{c}\text { Falta de } \\
\text { conhecimento do } \\
\text { processo }\end{array}$ & $\begin{array}{c}\text { Falta de } \\
\text { padronização para } \\
\text { procedimento }\end{array}$ & & & & $\begin{array}{c}\text { Falta de } \\
\text { padronização para } \\
\text { procedimento }\end{array}$ \\
\hline & & $\begin{array}{l}\text { Representante erra } \\
\text { respostas ao cliente }\end{array}$ & Falta de Feedback & $\begin{array}{c}\text { Falta de resposta } \\
\text { padrão para } \\
\text { fechamento do caso }\end{array}$ & & & & $\begin{array}{l}\text { Falta de resposta } \\
\text { padrão para } \\
\text { fechamento do caso }\end{array}$ \\
\hline & \multirow[t]{2}{*}{ MATERIAL } & $\begin{array}{l}\text { Cliente não recebe } \\
\text { resposta da } \\
\text { reclamação }\end{array}$ & $\begin{array}{l}\text { Cliente não atende o } \\
\text { telefone para receber } \\
\text { resposta da } \\
\text { solicitação }\end{array}$ & $\begin{array}{l}\text { Problema físico com } \\
\text { o aparelho do cliente }\end{array}$ & & & & $\begin{array}{l}\text { Problema físico com } \\
\text { o aparelho do cliente }\end{array}$ \\
\hline & & $\begin{array}{l}\text { Representante não } \\
\text { consegue enviar } \\
\text { respostas ao cliente }\end{array}$ & $\begin{array}{l}\text { Máquina com } \\
\text { defeitos }\end{array}$ & & & & & $\begin{array}{l}\text { Máquina com } \\
\text { defeitos }\end{array}$ \\
\hline \multirow{6}{*}{$\begin{array}{l}\text { ITEM: AVALIAÇÃO } \\
\text { DO CLIENTE ENTRE } \\
\text { MUITO RUIM, RUIM } \\
\text { E REGULAR (NOTAS } \\
\text { 1 A 3) }\end{array}$} & \multirow{2}{*}{ MEDIÇÃO } & $\begin{array}{l}\text { Sem mensuração de } \\
\text { SLA para } \\
\text { atendimento à } \\
\text { reclamação do } \\
\text { cliente }\end{array}$ & $\begin{array}{l}\text { Falta de relatório } \\
\text { específico para } \\
\text { acompanhamento }\end{array}$ & & & & & $\begin{array}{l}\text { Falta de relatório } \\
\text { específico para } \\
\text { acompanhamento }\end{array}$ \\
\hline & & $\begin{array}{c}\text { Sem análise das } \\
\text { notas } 1 \text { a } 3\end{array}$ & $\begin{array}{c}\text { Falta de } \\
\text { acompanhamento } \\
\text { dos problemas } \\
\text { diários encontrados } \\
\text { nas avaliações }\end{array}$ & $\begin{array}{c}\text { Falta de relatório } \\
\text { especifico para } \\
\text { identificação das } \\
\text { causas de avaliação } \\
\text { ruim }\end{array}$ & & & & $\begin{array}{l}\text { Falta de relatório } \\
\text { específico para } \\
\text { identificação das } \\
\text { causas de avaliação } \\
\text { ruim }\end{array}$ \\
\hline & \multirow[b]{2}{*}{$\begin{array}{c}\text { MEIO } \\
\text { AMBIEMTE }\end{array}$} & $\begin{array}{l}\text { Representante não } \\
\text { sabe as atualizações } \\
\text { de procedimento }\end{array}$ & $\begin{array}{c}\text { Falta de } \\
\text { conhecimento dos } \\
\text { novos processos }\end{array}$ & $\begin{array}{c}\text { Falta de repasse dos } \\
\text { novos processos }\end{array}$ & & & & $\begin{array}{l}\text { Falta de repasse dos } \\
\text { novos processos }\end{array}$ \\
\hline & & $\begin{array}{l}\text { Representante não } \\
\text { tem apoio para } \\
\text { resolver novos } \\
\text { problemas }\end{array}$ & $\begin{array}{c}\text { Falta de analista de } \\
\text { processos e } \\
\text { treinamento para } \\
\text { apoiar nos } \\
\text { procedimentos }\end{array}$ & $\begin{array}{l}\text { Falta de estrutura de } \\
\text { repasse de } \\
\text { informações para } \\
\text { operação que trata } \\
\text { as reclamações }\end{array}$ & & & & $\begin{array}{l}\text { Falta de estrutura de } \\
\text { repasse de } \\
\text { informações para } \\
\text { operação que trata } \\
\text { as reclamações }\end{array}$ \\
\hline & \multirow[b]{2}{*}{ MÉTODO } & $\begin{array}{c}\text { Operação não } \\
\text { acompanha indicador } \\
\text { qualitativo }\end{array}$ & $\begin{array}{c}\text { Falta de repasse dos } \\
\text { controles qualitativos } \\
\text { para apoio à } \\
\text { evolução da } \\
\text { operação }\end{array}$ & $\begin{array}{c}\text { Falta de relatórios de } \\
\text { controle qualitativo }\end{array}$ & & & & $\begin{array}{l}\text { Falta de relatórios de } \\
\text { controle qualitativo }\end{array}$ \\
\hline & & $\begin{array}{c}\text { Operação com } \\
\text { tratamento acima do } \\
\text { planejado }\end{array}$ & \begin{tabular}{|c|} 
Falta de \\
acompanhamento da \\
evolução de \\
reclamações \\
entrantes na \\
operação
\end{tabular} & $\begin{array}{c}\text { Falta de relatórios de } \\
\text { acompanhamento de } \\
\text { volume entrante de } \\
\text { reclamações }\end{array}$ & & & & $\begin{array}{l}\text { Falta de relatórios de } \\
\text { acompanhamento de } \\
\text { volume entrante de } \\
\text { reclamações }\end{array}$ \\
\hline
\end{tabular}

Fonte: Base de Avaliações disponibilizada pela Empresa A

Com base nos resultados do Brainstorming e respostas nos 5 Porquês, foi possível criar o Diagrama de Espinha de Peixe, conforme a Figura 10. Foi identificado que, em relação à categoria de Material: cenário encontrado de aparelho telefônico do cliente com defeito ou computador do representante de atendimento, com defeito; em relação à categoria de Mao de Obra: há cenários de Representante de Atendimento não realiza atendimento conforme procedimento, Representante de Atendimento realiza atendimento incorreto/incompleto, Ausência de padrão ou modelos a seguir para respostas específicas ao cliente; em relação à categoria de Máquina: cenário de Ausência de Ferramenta sistêmica para melhorar o atendimento, Sistema não critica quando representante marca dados incorretos para resposta ao cliente, Sem tecnologia suficiente para enviar mensagem ao cliente de outra forma que não seja por telefone; em relação à categoria de Método: Falta de controle qualitativo e Capacidade de tratamento de reclamações inferior ao planejado; em relação à categoria de Meio Ambiente: Falta de Conhecimento para melhoria contínua do atendimento e Falta de envolvimento das

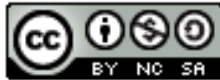


Citação (APA): Silva, C. R. R. \& Souza, W. R. de S., Jr. (2022). Estudo da utilização das ferramentas da qualidade para análise de causa raiz da baixa performance de atendimento em uma empresa de telecomunicações. Brazilian Journal of Production Engineering, 8(2), Edição Especial "Ciência na Prática", 145-162.

áreas para resolver os cenários de baixa avaliação; em relação à categoria de Medição: Ausência de meta clara para mensurar avaliação do atendimento e Dificuldade na mensuração de resultados para melhor acompanhamento das avaliações.

Figura 10. Diagrama de Causa e Efeito

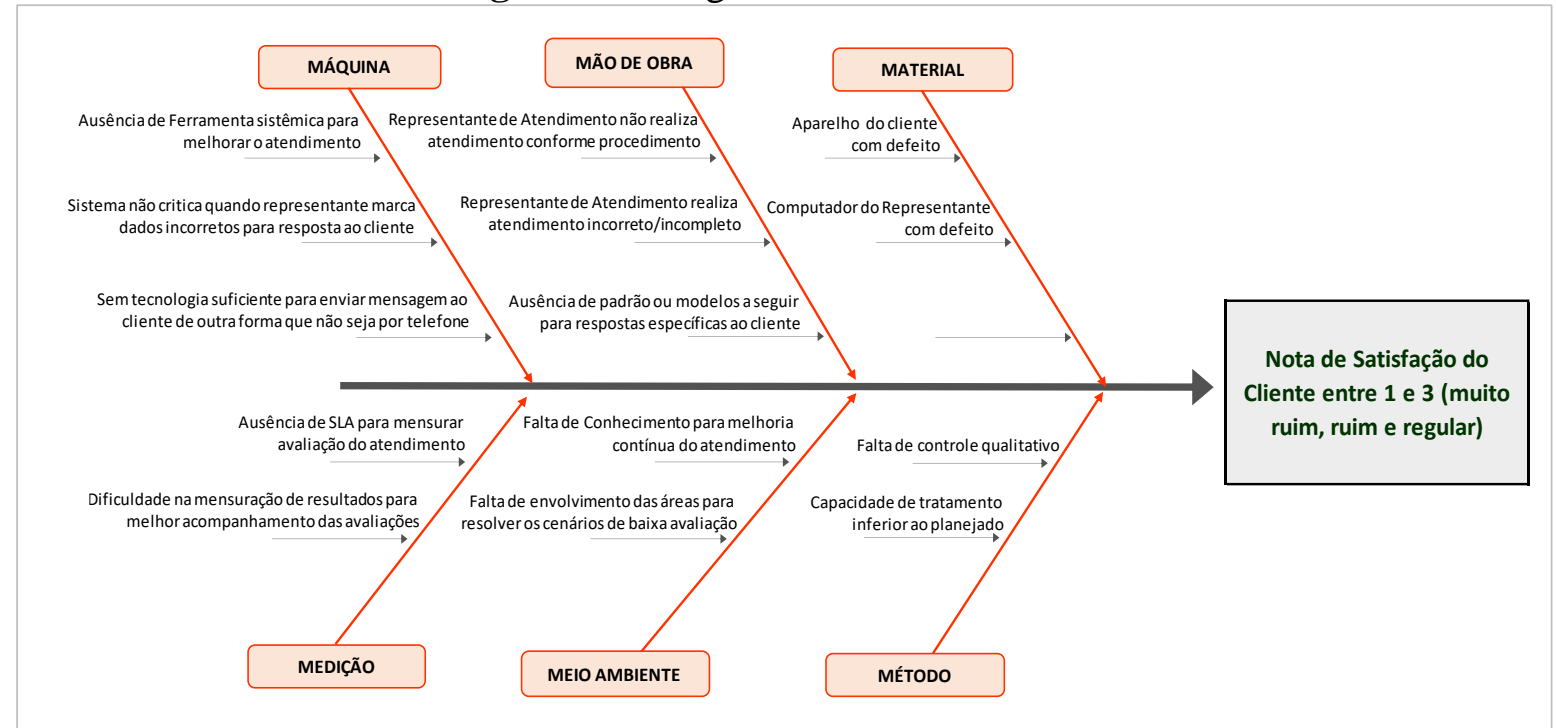

Fonte: Base de Avaliações disponibilizada pela Empresa A

Desta forma, após identificar as possíveis causas para a avaliação do cliente com notas 1 a 3 como pode ser visto na Figura 11, 12, 13, juntamente com a análise da matriz GUT para identificação dos cenários mais urgentes e pertinentes a ação imediata com a atribuição das notas de 1 a 5. Foram elencadas nove causas para criação do Plano de Ação.

Figura 11. Representação do Plano de Ação que foi desenvolvido com as 11 causas encontradas, de acordo com a priorização realizada na Matriz GUT.

\begin{tabular}{|c|c|c|c|c|c|}
\hline \multirow[t]{2}{*}{ CAUSA } & \multirow[t]{2}{*}{ CAUSA RAIZ } & G & U & T & TOTAL \\
\hline & & & URGÊNCIA & TENDÊNCIA & \\
\hline $\begin{array}{l}\text { Representante de Atendimento não realiza } \\
\text { atendimento conforme procedimento }\end{array}$ & $\begin{array}{l}\text { constantes para alinhamento de } \\
\text { procedimentos }\end{array}$ & 5 & 5 & 5 & 125 \\
\hline $\begin{array}{l}\text { Sistema não critica quando representante } \\
\text { marca dados incorretos para resposta ao } \\
\text { cliente }\end{array}$ & $\begin{array}{l}\text { Falta de desenvolvimento de sistemas } \\
\text { mais seguros para resposta ao cliente }\end{array}$ & 4 & 5 & 5 & 100 \\
\hline $\begin{array}{l}\text { mensagem ao cliente de outra forma que } \\
\text { não seja por telefone }\end{array}$ & $\begin{array}{l}\text { Falta de formas alternativas para se } \\
\text { comunicar com o cliente }\end{array}$ & 5 & 5 & 4 & 100 \\
\hline $\begin{array}{l}\text { Representante de Atendimento realiza } \\
\text { atendimento incorreto/incompleto }\end{array}$ & $\begin{array}{l}\text { Falta de feedback e alinhamento de } \\
\text { postura junto ao gestor }\end{array}$ & 5 & 5 & 4 & 100 \\
\hline $\begin{array}{l}\text { Ausência de padrão ou modelos a seguir para } \\
\text { respostas específicas ao cliente }\end{array}$ & $\begin{array}{l}\text { Falta de padrão de processos para } \\
\text { respostas prontas ao cliente }\end{array}$ & 5 & 4 & 5 & 100 \\
\hline $\begin{array}{l}\text { Falta de Conhecimento para melhoria } \\
\text { contínua do atendimento }\end{array}$ & $\begin{array}{l}\text { Falta de treinamento de novos } \\
\text { procedimentos }\end{array}$ & 4 & 5 & 4 & 80 \\
\hline Computador do Representante com defeito & $\begin{array}{l}\text { Falta de manutenção preventiva junto } \\
\text { ao Suporte/TI }\end{array}$ & 4 & 4 & 4 & 64 \\
\hline $\begin{array}{l}\text { Ausência de SLA para mensurar avaliação do } \\
\text { atendimento }\end{array}$ & $\begin{array}{l}\text { Falta de acompanhamento periódico } \\
\text { para controle da evolução do indicador } \\
\text { de avaliação }\end{array}$ & 4 & 4 & 4 & 64 \\
\hline $\begin{array}{l}\text { Dificuldade na mensuração de resultados } \\
\text { para melhor acompanhamento das } \\
\text { avaliações }\end{array}$ & $\begin{array}{l}\text { Falta de relatório minucioso com } \\
\text { acompanhamento visão representante } \\
\text { de atendimento }\end{array}$ & 4 & 4 & 4 & 64 \\
\hline $\begin{array}{l}\text { Falta de envolvimento das áreas para } \\
\text { resolver os cenários de baixa avaliação }\end{array}$ & $\begin{array}{l}\text { Falta de plano de atuação das áreas de } \\
\text { apoio nos cenários de baixa nota de } \\
\text { satisfação }\end{array}$ & 3 & 4 & 3 & 36 \\
\hline $\begin{array}{l}\text { Capacidade de tratamento inferior ao } \\
\text { planejado }\end{array}$ & $\begin{array}{l}\text { Falta de acompanhamento do volume } \\
\text { de reclamações entrantes por REP/DIA }\end{array}$ & 3 & 4 & 3 & 36 \\
\hline
\end{tabular}

Fonte: Base de Avaliações disponibilizada pela Empresa A 
O cenário de maior impacto em relação à Gravidade (5), Urgência (5) e Tendência (5) é a causa "Representante de Atendimento não realiza atendimento conforme procedimento". Este cenário é considerado de risco alto se não for realizado conforme regras pois, se o representante não sabe o processo correto para informar ao cliente e/ou realiza o processo incorreto junto ao cliente, pode gerar, além da má avaliação, multa por erros financeiros, além do impacto da credibilidade na organização. É um cenário extremamente grave, que precisa de ação imediata e que com certeza irá piorar rapidamente se nada for feito. A segunda causa com maior impacto é "Sistema não critica quando representante marca dados incorretos para resposta ao cliente", ou seja, se o representante de atendimento incluir informação divergente ou incompleta no cadastro do cliente, não há uma crítica sistêmica. Isso significa falta de padrão e risco de inserção de dados incorretos na ficha do cliente junto à empresa. Desta forma, é necessário que seja desenvolvido um sistema seguro pra cadastro de dados e respostas aos clientes, a fim de evitar cenários de respostas incorretas e/ou incompletas e, de novo, gerar insatisfação, prejuízo financeiro e perda de credibilidade da companhia. É um cenário muito grave, precisa de ação imediata, e irá piorar rapidamente se nada for feito.

Identificadas as principais causas para avaliação ruim do cliente e os cenários com maior urgência para ação imediata. Principalmente os cenários de treinamento contínuo de procedimentos e desenvolvimento de sistemas com melhor comunicação com o cliente são os principais passos para melhora da nota de satisfação desta operação.

Figura 12. Plano de Ação - 5W2H

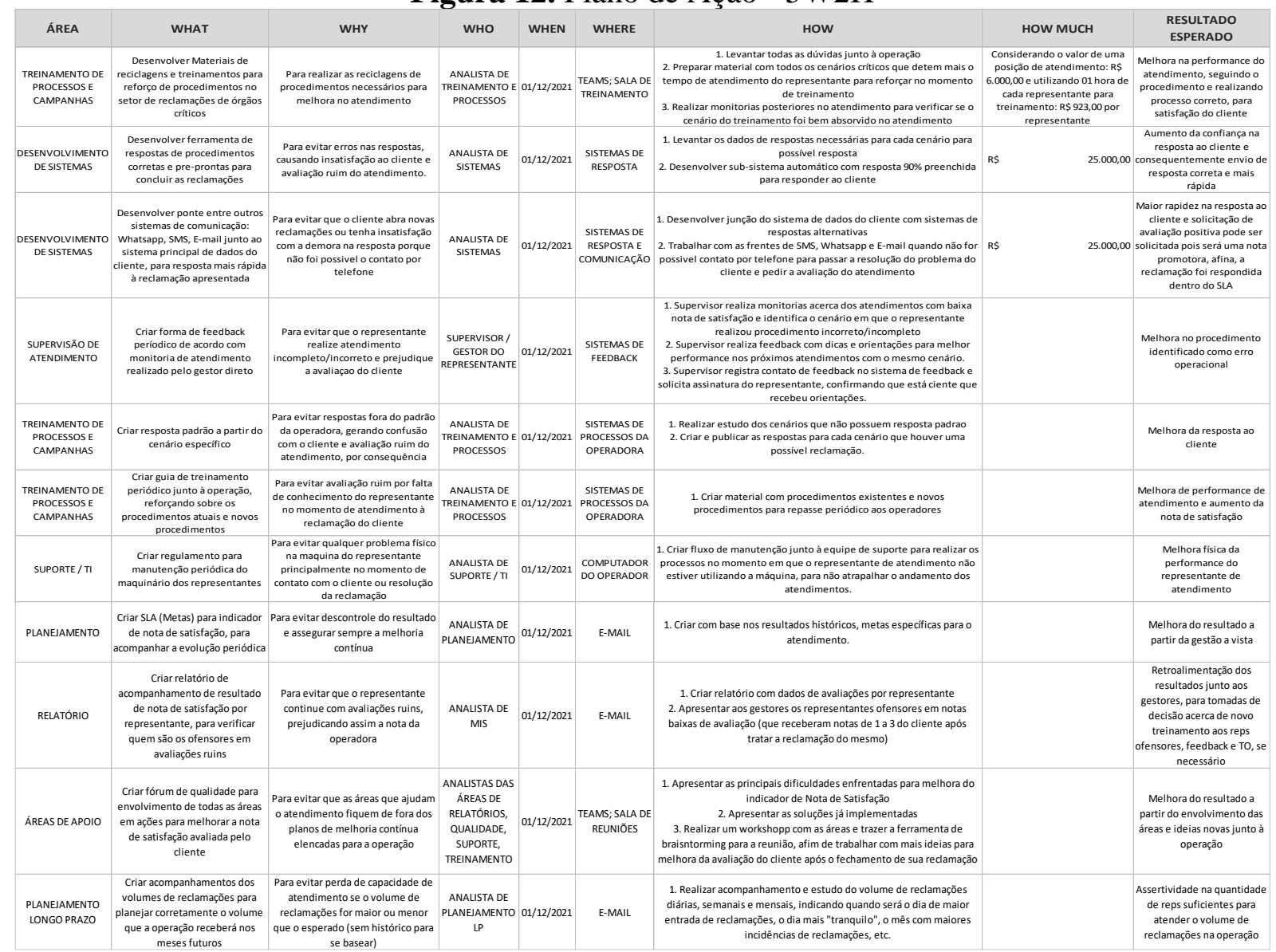

Fonte: Resoluções com base nas Avaliações disponibilizada pela Empresa A 
Citação (APA): Silva, C. R. R. \& Souza, W. R. de S., Jr. (2022). Estudo da utilização das ferramentas da qualidade para análise de causa raiz da baixa performance de atendimento em uma empresa de telecomunicações. Brazilian Journal of Production Engineering, 8(2), Edição Especial "Ciência na Prática", 145-162.

\section{CONSIDERAÇÕES FINAIS}

O presente artigo foi desenvolvido sob um detalhado estudo com levantamentos de dados e análises direcionadas a uma empresa de prestação de serviços de Telecomunicações, considerando a resposta que a organização recebe ao atender uma reclamação de um cliente de telefonia. O objetivo geral deste trabalho foi confirmado a partir da utilização das ferramentas da qualidade, aplicadas de forma coerente, que auxiliaram de forma clara e positiva na identificação da causa raiz e soluções de problemas. Foi possível desenvolver um plano de ação a médio e longo prazo, soluções factíveis para evolução dos processos que envolvem o atendimento final que acarreta na satisfação do cliente e na boa avaliação do mesmo. Confirmando a hipótese levantada, foi possível identificar onde estava o problema principal através do diagrama de Pareto, traçar as causas mediante ideias no Brainstorming, 5 Porques e diagrama de Ishikawa e encontrar, através da Matriz GUT e 5W2H, as ações necessárias para melhoria contínua dos cenários apresentados.

Inicialmente, foi realizado uma visita à Empresa A, para conhecer os fluxos e o que será estudado. Foi pesquisado a forma como o atendimento às reclamações do cliente funcionam. Após a disponibilização dos dados que datam de Setembro de 2021, foram encontrados 7.246 registros de atendimentos com avaliações realizadas pelos clientes. Com os registros disponibilizados, foram filtradas as avaliações com notas de 1 a 3 para analisar o motivo do cliente avaliar mal o atendimento prestado. Nesta base, foram encontradas 2.083 avaliações de 1 a 3 na base de reclamações da operadora $72,30 \%$ das avaliações encontradas são de nota 1 . Foi utilizada o gráfico de Pareto para identificar os principais motivos de entradas que levam os clientes a entrarem em contato com o atendimento e foram encontrados 6 motivos principais que detém $80 \%$ do total de reclamações com avaliações de 1 a 3 . Os itens significativos, priorizados no gráfico de Pareto, totalizam 1.664 avaliações do total da base. Deste volume, 72,9\% são de avaliações com Nota 1 (Muito Insatisfeito), 9,4\% são de Nota 2 (Insatisfeito) e $17,7 \%$ são de avaliações identificadas com Nota 3 (Neutro).

Após a identificação dos motivos principais de acordo com o Diagrama de Pareto, foi possível realizar um Brainstorming junto aos analistas da qualidade. A partir da ferramenta dos 5 Porques, foi traçado o segundo passo para descobrir a causa raiz da queda de nota de satisfação do cliente junto à operadora. Logo após foi utilizado o Diagrama de Ishikawa para Identificação dos Sub-itens ofensores. Com base nos resultados do Brainstorming e respostas nos 5 Porquês, foi possível criar o Diagrama de Espinha de Peixe com as causas Raiz. Desta forma, foi possível montar uma matriz GUT para identificação dos cenários mais urgentes e pertinentes a ação imediata. Foram elencadas 9 causas para criação do Plano de Ação.

Identificadas as principais causas para avaliação ruim do cliente e os cenários com maior urgência para ação imediata. O Plano de Ação foi desenvolvido com as 11 causas encontradas, de acordo com a priorização realizada na Matriz GUT.

Com a correta utilização das ferramentas da qualidade, foi possível encontrar onde estavam os gaps do processo. Utilizando o fluxo, foi possível ver onde começa e termina a ação do operador junto à reclamação do cliente. A partir da base de informações e com o conhecimento que o Diagrama de Pareto fornece, foi possível traçar onde estavam concentrados os principais 
Citação (APA): Silva, C. R. R. \& Souza, W. R. de S., Jr. (2022). Estudo da utilização das ferramentas da qualidade para análise de causa raiz da baixa performance de atendimento em uma empresa de telecomunicações. Brazilian Journal of Production Engineering, 8(2), Edição Especial "Ciência na Prática", 145-162.

problemas no atendimento que geravam notas de 1 a 3 . Assim, mediante o Brainstorming e os 5 Porques, foi possível identificar os motivos necessários para montar o Diagrama de Ishikawa, onde identificamos as causas raízes dos problemas de atendimento. Desta forma, foi possível traçar a matriz de Priorização e o Plano de ação, para que os problemas encontrados sejam resolvidos e aconteça a melhoria contínua dos processos.

Não foi analisado dados após o estudo de caso aplicado para identificar quantitativamente e qualitativamente se houve e melhora na avaliação do cliente.

\section{REFERÊNCIAS}

Almeida, E. M., de. \& Grande, M. M. (2020). Qualidade na prestação de serviços por meio de tecnologias de autoatendimento uma revisão de literatura. Anais do Encontro Nacional de Engenharia de Produção, Foz do Iguaçu, PR, Brasil, 40.

Alves, J. S. \& Santos, B. F., Jr. (2019). O uso das ferramentas da qualidade para a melhoria no setor de atendimento ao cliente. Anais do Simpósio de Engenharia de Produção, Sergipe, 11. São Cristóvão, SE, 117-126.

Cavalcanti, R. C. \& Farias, J. R., de, Filho. (2015). Ferramentas da qualidade auxiliando na otimização dos processos do setor de manutenção: um estudo de caso na indústria automobilística. Anais do Congresso Nacional De Excelência Em Gestão. Recuperado de https://www.inovarse.org/sites/default/files/T 15395 1.pdf

Coelho, A. J. F., Silva, J. V. T., da., Paiva, W. F., \& Xacier, T. D. N. (2019). Aplicação das ferramentas da qualidade para melhoria no processo e resolução de problemas em uma panificadora. Anais do Encontro Nacional de Engenharia de Produção, Santos, SP, Brasil, 39. Conceição, A. R. \& Rodrigues, A. C. E. (2019). Análise e proposta para a solução da baixa produtividade na estufa do unasp-ec estudo de caso e aplicação das metodologias masp, pdca e dmaic. Anais do Encontro Nacional de Engenharia de Produção, Santos, SP, Brasil, 39.

Correa, P. F., \& Oliveira, L. B., de. (2017). Aplicação das ferramentas da qualidade na solução de problemas de contaminação em uma fábrica de chocolate. Revista de Engenharia e Pesquisa Aplicada, 2(2), 86-101. Recuperado de https://pdfs.semanticscholar.org/faa8/ffa6f069e6aea62c5e3832d186d82ee73d3b.pdf?_ga=2.4 6715492.217155563.1646752121-1735981152.1646752121

Melo, C. A., da S., Melo, F. J. C., Jerônimo, T. de B., \& Aquino, J. T., de. (2016). Uso gerencial das ferramentas da qualidade pelo decisor: um estudo de caso sobre o problema de aquisição de materiais pelas Atas de Registro de Preços em uma empresa pública militar. Exacta, 14(2), 235-250. https://doi.org/10.5585/exactaep.v14n2.6234

Silva, J. M., da., Pereira, T., \& Olivo, A. M. (2016). Estudo da aplicação de ferramentas da qualidade em uma linha de envase numa Indústria Alimentícia. Colloquium Exactarum. 8(4), 24-3). Recuperado de https://revistas.unoeste.br/index.php/ce/article/view/1900

Coelho, F. P. de S., Silva, A. M., da., \& Maniçoba, R. F. (2016). Aplicação das ferramentas da qualidade: estudo de caso em pequena empresa de pintura. Refas-Revista Fatec Zona Sul, 3(1), $31-45$.

Recuperado

de

http://www.revistarefas.com.br/index.php/RevFATECZS/article/view/70

Ensslin, L., Ensslin, S. R., Lacerda, R. T. D. O., \& Tasca, J. E. (2010). ProKnow-C, Knowledge Development Process-Constructivist: processo técnico com patente de registro pendente junto ao INPI. Brasil:[sn].

Borges, R., Berghauser, N. A. C., \& Fabris, C. B. (2014). Aplicação das ferramentas da qualidade em um processo produtivo em uma indústria de ração (Monografia, Universidade 
Citação (APA): Silva, C. R. R. \& Souza, W. R. de S., Jr. (2022). Estudo da utilização das ferramentas da qualidade para análise de causa raiz da baixa performance de atendimento em uma empresa de telecomunicações. Brazilian Journal of Production Engineering, 8(2), Edição Especial "Ciência na Prática", 145-162.

Tecnológica Federal do Paraná). Recuperado de http://educapes.capes.gov.br/handle/capes/172079

Freitas, L. R., Maia, G. L., Costa Filho, J. L. L. D., \& Carneiro, J. M. (2020). Aplicação da metodologia de análise e solução de problemas em um centro de distribuição de cosméticos. Simpósio de Engenharia de Produção, XXVII, Bauru, São Paulo, Brasil. Recuperado de http://www.repositorio.ufc.br/handle/riufc/59614

Gomes, A. C. N., Ferreira, A. R. D. S. V., \& Silva, E. B. (2018). A aplicação das ferramentas da qualidade em estabelecimentos de Food Service. XXXVIII Encontro Nacional de Engenharia de Produção. "A Engenharia de Produção e suas contribuições para o desenvolvimento do Brasil". Maceió, Alagoas, Brasil. Recuperado de http://www.abepro.org.br/biblioteca/TN_STO_259_491_35855.pdf

Holanda, Y. L., Aires, R. F. de F., \& Salgado, C. C. R. (2020). Ferramentas para melhoria da qualidade um estudo de caso. Anais do Simpósio de Engenharia de Produção, Bauru, SP, Brasil, 27.

Iaksch, J. S., Volpato, N., Borsato, M., Vaine, A., \& Shigueoka, M. O. (2019). Planejamento de processo na manufatura aditiva por extrusão: uma análise bibliométrica e sistêmica. $10^{\circ}$ Congresso Brasileiro de Engenharia de Fabricação. São Carlos, SP, Brasil. http://dx.doi.org/10.26678/ABCM.COBEF2019.COF2019-0348

Ieiri, L. F., Romão, J. M. R., Jr., Barreto, E. A., \& Antunes, J. M. F., Neto. (2020). Aplicação de ferramentas de melhoria continua da qualidade na análise de papelão ondulado: estudo de caso. Prospectus, 2(2), 224-243. https://doi.org/10.5281/zenodo.5565175

Jenges, R. \& Bilibio, D. (2018). Ferramentas da qualidade: Uma solução para reduzir os desperdícios e aumentar a produção em uma indústria moveleira. Mundo Contemporâneo em Revista, 5(01), 164-177.

Lima, G. P., Fornari, C., Aquino, M., \& Figueredo, P. (2020). Aplicação da metodologia PDCA no desenvolvimento de compósitos biodegradáveis de fibra de coco e amido modificado. Revista Eletrônica Produção \& Engenharia, 10(1), 815-826. https://doi.org/10.34019/19839952.2020.v10.29709

Meireles, C. C., Aquino, J. R., de., Santos, M. dos., \& Walker, R. A. (2019). Proposta de melhoria nos serviços de um restaurante de comida japonesa a partir das ferramentas da qualidade. $1^{o}$ Seminário de Sistema Lean, Limeira.

Mello, M. F., Cunha, L. A., Silva, N. J., \& Araújo, A. C. (2017). A importância da utilização de ferramentas da qualidade como suporte para melhoria de processo em indústria metal $\begin{array}{lllll}\text { mecânica-um estudo de } \quad \text { caso. } & \text { Exacta, }\end{array}$ https://doi.org/10.5585/exactaep.v15n4.6898

Meneses, V. N., de., Frasao, S. C., Araujo, F. das C. M. de, Filho., Sousa, K. P. de., Lima, Y. C. C., de. (2017). A aplicação de ferramentas da qualidade em uma indústria metalúrgica de produtos de aço. Anais do Encontro Nacional de Engenharia de Produção, Joinvile, SC, Brasil, 37.

Moreira, G. M., Lima, J. A. S., Lima, L. de S., Pinto, R. S. (2020). Estudo de caso de uma indústria metalúrgica - aplicação das ferramentas da qualidade. Anais do Encontro Nacional de Engenharia de Produção, Foz do Iguaçu, PR, Brasil, 40.

Moura, L. F., da. \& Rodrigues, L. M. (2019). Aplicação das ferramentas da qualidade melhoria no tempo de tramitação do processo de aquisição de bens materiais e na contratação de serviços. Anais do Encontro Nacional de Engenharia de Produção, Santos, SP, Brasil, 39. 
Muniz, G. F., Monteiro, M. P., Dias, W. C., Fioravante, I. A., Fernandes, L. F. V. M., \& Ribeiro, R. B. (2016). Análise da causa raiz no processo produtivo por meio do uso das ferramentas da qualidade. DI Factum, 1(1), 75-81.

Neto, J. L. P. \& Chiquetano, R. M. M. D. (2020). Gestão da qualidade: uso conjunto do google forms e diagrama de pareto no setor de atendimento ao cliente. Anais do Encontro Nacional de Engenharia de Produção, Foz do Iguaçu, PR, Brasil, 40.

Penedo, L. S., Carvalho, J. T., de., Costa, W. L., Andrade, M. M. E., de., Galvão, T. W. D. F. B., \& Galvão, T. W. D. F. B. (2020). Utilização das ferramentas da qualidade nos processos de manutenção, visando o desperdício de tempo e a produtividade. Revista Eletrônica TECCEN, 13(1), 16-24.

Pierre, F. C. \& da Silva, F. A. (2020). Utilização de ferramentas de qualidade para análise de não conformidades em um processo de produção em uma indústria metalúrgica. Tekhne $e$ Logos, 11(2), 66-81.

Ramos, L. T., Oliveira, R. D., \& Azevedo, R. C. (2019). Revisão bibliométrica aplicada ao uso de sistemas vegetados verticais em simulações de desempenho térmico de edificações. $X V$ ENCAC - Encontro Nacional de Conforto no Ambiente Construído e XI ELACAC - Encontro Latino-Americano de Conforto no Ambiente Construído. João Pessoa, Brasil.

Reno, G. W. S. (2015). Aplicação das ferramentas da qualidade para redução na quebra de prendedores de roupa em uma empresa de injeção de plásticos. Anais do Encontro Nacional de Engenharia de Produção, Fortaleza, CE, Brasil, 35.

Rodrigues, C. L., Martins, H., dos S., Praxedes, G. M., Nobre, M. B., \& Tenório, C. C. (2020). Aplicação de ferramentas da qualidade na avaliação dos serviços prestados em uma escola pública. Anais do Encontro Nacional de Engenharia de Produção, Foz do Iguaçu, PR, Brasil, 40 .

Santos, A. S. R., Scaquetti, R. A. B., Azevedo, S. A., de., \& Bernini, D. S. D. (2020) A aplicação das ferramentas da qualidade para a melhoria de um processo industrial. Anais do Encontro Nacional de Engenharia de Produção, Vitória, ES, Brasil, 40.

Santos, K. R. B. \& Vasconcelos, M. E. S. S. (2019). Utilização de ferramentas da qualidade como método de melhoria no atendimento: um estudo de caso em uma unidade básica de saúde no município de Campos dos Goytacazes. Anais do Simpósio de Engenharia de Produção, Bauru, SP, Brasil, 26.

Silva, D. A., da., Cesar, F. I. G., Moraes, A. J. I., de., \& Neto, L. V. (2019). Análise da aplicação dos princípios, técnicas e ferramentas da industria 4.0 no controle da qualidade total. Anais do Encontro Nacional de Engenharia de Produção, Santos, SP, Brasil, 39.

Silva, T. G. E., Lago, G. O., \& Menezes, M. T. C. S. (2020). O uso das ferramentas de qualidade para melhoria do indicador de acuracidade de uma empresa prestadora de serviços em gestão de recursos humanos. Anais do Encontro Nacional de Engenharia de Produção, Foz do Iguaçu, PR, Brasil, 40.

Silva, A. B. \& Pereira, A. A. (2004). Fatores de influência na gestão das empresas de pequeno e médio porte da grande Florianópolis/SC. Anais do Encontro Nacional da Associação Nacional de Pós-Graduação e Pesquisa em Administração, Curitiba, PR, Brasil, 28.

Tássia, A., \& de Oliveira, L. B. (2020). Aplicação de Ferramentas da Qualidade para Análise e Solução de não Conformidades em uma Indústria de Alumínio. Revista de Engenharia e Pesquisa Aplicada, 5(4), 48-58. 